\title{
Transverse and Longitudinal Stress Analysis in Reinforced Welded Oil Branched Pipes
}

\author{
H Safari ${ }^{\mathrm{a}}, \mathrm{R}$ Pourrajab ${ }^{\mathrm{a}}$ and AYaghootian \\ National Iranian South Oil Company (NISOC), Ahvaz, Iran \\ Department of Mechanical Engineering, Shohadaye Hoveizeh University of Technology, Khuzestan, Iran \\ Department of Mechanical Engineering, Shahid Chamran University of Ahvaz, Ahvaz, Iran
}

\begin{abstract}
Welding process results in the non-uniform distribution of heat. Combined with thermal strain, plastic deformation and welding-induced distortion, it causes important problems such as failure. This study models welding process in a $12 \times 16$ split tee junction using finite element. This junction is a reinforcing branch used in the hot taping of oil pipe line. The model is studied in 3D state. This zone, i.e. heat affected zone (HAZ) is of high importance due to the existence of a severe temperature gradient and stress in the vicinity of HAZ. This study analyses single pass butt welding with a cooling time of 2700 seconds. In order to apply boundary conditions to the model, the studied structure should be in Free State according to practical procedure. The main aim of this simulation is to analyse Longitudinal and transverse residual stresses originated from co-directional and opposite-directional welding. This joint is formed of two semicircles welded to each other as linear single pass welding. Two welders simultaneously welded both sides of the pipe.
\end{abstract}

\section{Introduction}

In industrial factories, oil and gas refineries, petrochemical industries, thermal power plants, oil product pipelines and gas pipelines, there may be immediate need for cutting and welding operations on pipelines carrying hot, high pressure, flammable and toxic fluids. In such conditions, the operations should inevitably be done while the pipes are in service. The so-called hot tap technique is used for this purpose. According to studies, the majority of defects and failures in such junctions occur in the HAZ of carbon steels. The residual stress of welding serves as the main cause of the defects in the junctions [1]. Having an accurate prospect of the size and distribution of stresses as well as the effect of different welding parameters on residual stresses plays a vital role in controlling and minimizing their problems. Jiang and Yahiaoui [2] studied the effect of welding sequence on residual stress distribution in a multi-pass welded piping branch junction. High residual stress was formed in the vicinity of the weld region, irrespective of the sequence of welding. Deng et al [3] analysed the influence of deposition sequence on welding residual stress and deformation in an austenitic stainlesssteel J-groove welded joint. Their results showed that welding sequence not only has a significant effect on results but it results in a significant change in the shape of deformation modes induced by welding sequence. Yaghi et al [4] evaluated residual stresses induced by dissimilar welding of a P92 steel pipe with weld metal IN625 using finite element simulation. Two subroutines were developed, one of which prescribed two phases of P92 steel while the other assumed three phases. Skouras et al

\footnotetext{
${ }^{\text {a } H o s s e i n . s a f a r i 86 @ g m a i l . c o m ; ~ r . p o u r r a j a b @ g m a i l . c o m ~}$
} 
[5] measured welding-induced residual stresses in a P92 steel-In625 supperalloy metal in as welded and post welded heat-treated conditions. The results were discussed with respect to the residual stress magnitude and location as well as with respect to the effectiveness of the post welded heat-treatment procedure. $\mathrm{Fu}$ et al [6] analyzed the effect of welding sequence on residual stressed in a thin-walled octagonal pipe-plate structure. Nine different simulation sequences were carried out by single-pass TIG welding of an octagonal pipe-plate joint and the distribution of longitudinal and transverse residual stresses both on the outer and inner surfaces of the pipe were analyzed. Bajpei et al [7] evaluated the mitigation of residual stresses and distortions in thin aluminium alloy GMAW plates using different heat sink models. Their results show a good conformity between experimental and numerical results. This study analyzes the effect of welding-induced residual stresses on split tee reinforcing branch in a pipe-shaped joint of carbon steel (ASTM A36). The review of previous studies showed that there is no study on this subject. Co-directional and opposite-directional welding techniques were first modelled using ANSYS finite element. Then, the analysis results of Longitudinal and transverse residual stresses were studied in both welding techniques.

\section{Modeling}

\subsection{Mechanical analysis}

To simplify the welding simulation, the thermal and mechanical analyses were performed successively. Thermal analysis first determined heat distribution model during welding process. Then, the temperature history was applied to mechanical model as thermal load and stress distribution was obtained by solving the mechanical model. All items of mechanical model, except element type and boundary conditions, are similar to thermal model. Thermal model was obtained using the 3D element SOLID 70 with eight quadrilateral nodes with a single degree of freedom having temperature at each node while mechanical model was analyzed using the 3D element SOLID 185 with eight quadrilateral nodes; each have three degrees of freedom. In order to apply boundary conditions to the model, the structure should be in Free State in accordance with practical procedure. The studied junction is a $12 \times 16$-inch junction. Figures 1 and 2, and table 1, show the geometry and dimensions of the model, respectively. This model is studied in $3 \mathrm{D}$ state. Figure 3 shows the model meshing. There is a strong thermal gradient and stress in the vicinity of HAZ and this zone is of high importance [8,9]. Therefore, finer meshes were used in this zone. It is impossible to generate or remove elements during solution process. Therefore, all elements already be created. To this ends, element birth and death capability was used [10].

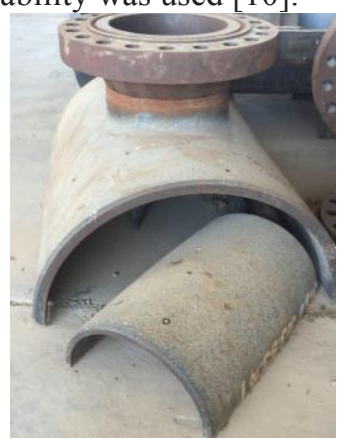

Figure 1. View of the model.

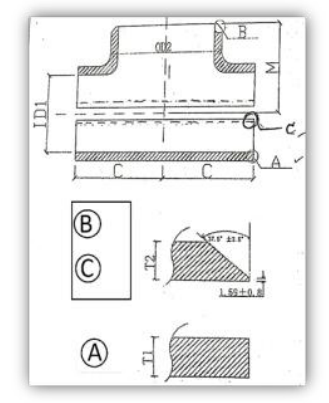

Figure 2. Dimension of split tee.

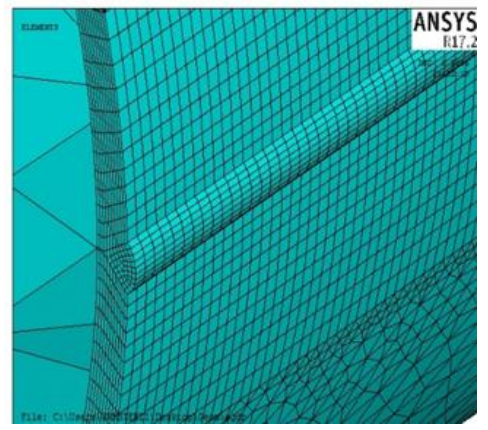

Figure 3. The model meshing. 
Table 1. Dimension of split tee (Figure 2).

\begin{tabular}{cccccccc}
\hline $\begin{array}{c}\text { Size } \\
\text { (inch })\end{array}$ & $\begin{array}{c}\text { WT } \\
(\mathrm{mm})\end{array}$ & $\begin{array}{c}\text { ID1 } \\
(\mathrm{mm})\end{array}$ & $\begin{array}{c}\text { OD2 } \\
(\mathrm{mm})\end{array}$ & $\begin{array}{c}\mathrm{C} \\
(\mathrm{mm})\end{array}$ & $\begin{array}{c}\mathrm{M} \\
(\mathrm{mm})\end{array}$ & $\begin{array}{c}\text { T1 } \\
(\mathrm{mm})\end{array}$ & $\begin{array}{c}\text { T2 } \\
(\mathrm{mm})\end{array}$ \\
\hline $16 \times 12$ & 9.5 & 406.4 & 232.9 & 304.8 & 295.3 & 9.5 & 9.5 \\
\hline
\end{tabular}

\subsection{Thermal analysis}

There are two main approaches to modelling input heat source in modelling welding process. The first one is to apply heat to a given volume of fusion zone in order to form an acceptable volume of melted material. The second one deals with the application of thermal flux or input heat source modelling [11]. This study required a large amount of calculations demanding a very specific system. Therefore, it adopted melting temperature method $[9,12]$. Convection heat transfer coefficient in central line was zero due to the symmetry of the line and was considered to be $15\left(\mathrm{~W} . \mathrm{m}^{2}\right) / \mathrm{c}$ in other surfaces. Ambient temperature was assumed $18^{\circ} \mathrm{C}[8,9,13,14]$. In this study, a constant heat was applied in each pass which was proportional to welding time and the position of welded elements.

\subsection{Material specifications}

With a ferrite and perlite microstructure, carbon steel (ASTM A36) is widely used in structures and equipment in dry lands. It shows acceptable welding property with no specific behaviour during welding. This simulation considers the same properties for the base metal, HAZ and welding metal $[15,16]$.

\section{Results and discussion}

\subsection{Analysis of residual stress induced by co-directional and opposite directional welding}

Figure 4 shows transverse residual stress of a selected path, which is perpendicular to welding line. According to this figure, in both co-directional and opposite-directional welding methods the type of stress is tensile stress from the highest to the lowest part of the studied model. By moving away from the welded zone, tensile stress decreases and it is converted to compressive stress. Finally, form a given distance the type of stress changes to tensile stress again. Figure 5 shows transverse residual stress distribution.

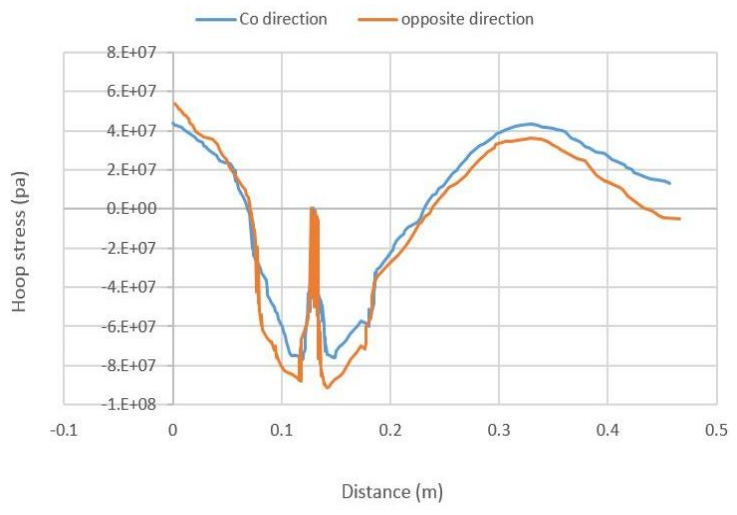

Figure 4. transverse residual stress in the selected curve for both co-directional and oppositedirectional welding methods

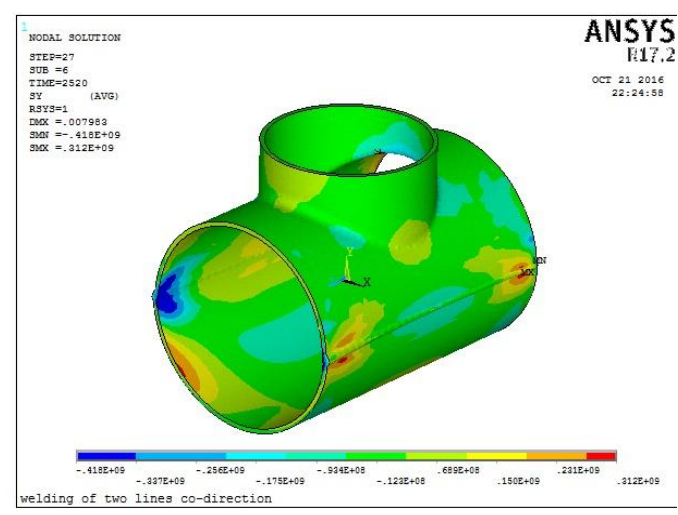

Figure 5. transverse stress in co-directional welding $($ time $=2520)$ 
Figure 6 compares co-directional welding with opposite-directional one. According to the figure, the value of residual stress has a tensile peak in the selected path. This point, on which the tensile stress becomes the maximum, is the point in which the two parts are welded to each other. After this point, the type of stress becomes compressive with a steep slope and finally the stress approaches a constant value. Figure 7 shows longitudinal residual stress distribution in different times.

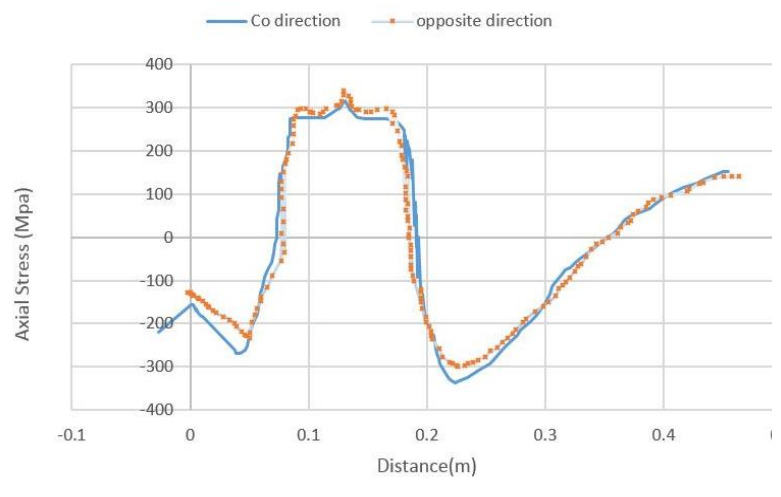

Figure 6. longitudinal residual stress in the selected curve in both co-directional and opposite-directional welding methods

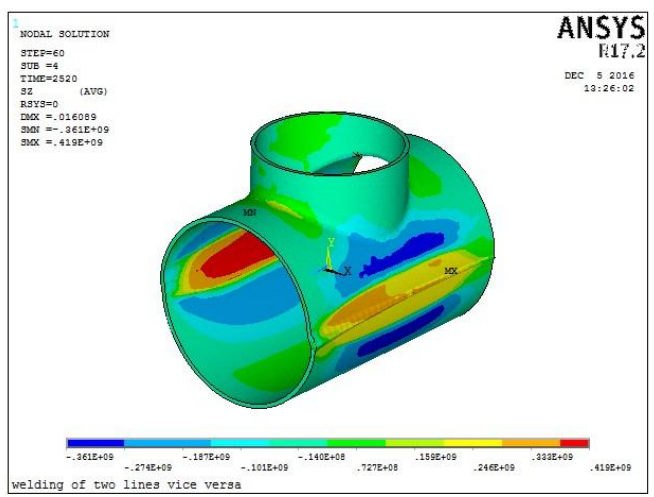

Figure 7. Longitudinal residual stress in opposite-directional welding $($ time $=2520)$

\section{Conclusions}

Analyse Longitudinal and transverse residual stresses originated from co-directional and oppositedirectional welding were is studied in 3D state by using ANSYS finite element. Following conclusions are presented based on the Finite Element results:

$>$ A large longitudinal tensile residual stress is created around HAZ and this value decreases away from HAZ.

$>$ The maximum transverse residual stress is created in fusion zone. In far zones this stress almost tends to zero.

$>$ The value of longitudinal residual stress in opposite-directional welding is slightly higher than that of co-directional welding.

$>$ By moving electric arc and the deposition of welding beginning and ending effects in HAZ, transverse stress distribution was experienced considerable change.

\section{Acknowledgement}

Authors thank National Iranian oil company (NIOC), National Iranian South oil company (NISOC) and Marun Oil and Gas Producing Company (MOGPC) for their help and financial support.

\section{References}

1. T. Teng, P. Chang, W. Tseng, "Effect of welding sequences on residual stresses," Computers and Structures, (81),(2003). 
2. W. Jiang, K. Yahiaoui, " Effect of welding sequence on residual stress distribution in a multipass welded piping branch junction", International Journal of Pressure Vessels and Piping,(95), (2012).

3. D. Deng, "Influence of deposition sequence on welding residual stress and deformation in an austenitic stainless steel J-groove welded joint”,Materials and Design,(49),(2013).

4. A.H. Yaghi, T.H. Hyde, A.A. Becker, W. Sunb, “Finite element simulation of residual stresses induced by the dissimilar welding of a P92 steel pipe with weld metal IN625",International Journal of Pressure Vessels and Piping,(2013).

5. A. Skouras, P.E.J. Flewitt, M. Peel, M.J. Pavier, "Residual stress measurements in a P92 steelIn625 superalloy metal weldment in the as-welded and after post weld heat treated," International Journal of Pressure Vessels and Piping, (123-124), (2014).

6. D.f. Fu, Ch. Zhou, C. LI, G. Wang, L.LI, "Effect of welding sequence on residual stress in thinwalled octagonal pipe-plate structure," Transactions of Nonferrous Metals Society of China,3(24),(2014).

7. T. Bajpei, H. Chelladurai, M. Zahidansari, "Mitigation of residual stresses and distortions in thin aluminium alloy GMAW plates using different heat sink models," Journal of Manufacturing Processes,(22), (2016)

8. S.h. Cho, J.w. Kim, "analysis of residual stress in carbon steel weldment incorporating phase transformation," science and technology of welding and joining,4(7), (2002).

9. L. Yajiang, W. Lura, C. Maoi, S. Xiaoqin, "finite element analysis of residual stress in the welded zone of high strength steel," Bulletin of Materials Science, 2(27),(2004).

10. Ansys, Rev 17.0,Ansys,Inc., Canonburg,PA,(2000).

11. D. Naeem, "Analysis of weld-induced residual stresses and distortions in thin-walled cylinders,” ,Journal of Mechanical Science and Technology ,(23), (2009).

12. B. Taljat, B. Radhakrishnan, T. Zacharia ,"numerical analysis of GTA welding process with emphasis on post solidification phase transformation effects on residual stresses," materials science and engineering, 1-2(246), ,(1998)

13. B.A.B. Andersson," thermal stresses in submerged-arc welded joint considering phase transformations," Journal of Engineering Materials and Technology, (100), (1978).

14. J. Goldak , A. Chakrorati, M.G. Bibby, " A new finite element model for welding heat sources," metallurgical tranctions ,2(15), (1984).

15. P.H. Chang, T.L. Teng, "numerical and experimental investigations on the residual stresses of butt-welded joints," computational materials science,4 (29), (2004).

16. S. Wen, P. Hilton, D. C Farragia, "finite element modeling of submerged arc welding process," journal of materials processing technology,1(119), (2001). 